\title{
PLASMA-OXYGEN INTERACTION DURING THIN FILMS DEPOSITION BY LASER ABLATION: DETERMINATION OF THE INTERACTION PRESSURE THRESHOLD AND EFFECT ON THE THIN FILMS PROPERTIESE
}

\author{
S. Lafane*, T. Kerdja, S. Abdelli-Messaci, Y. Khereddine and M. Kechouane
}

Centre de développement des technologies avancéesCité 20 août 1956, B. P. 17, Baba

Hassen, Algérie

Received: 25 November 2012 / Accepted: 02 December 2012 / Published online: 30 June 2012

\begin{abstract}
In this contribution we study the effect of the oxygen pressure on the plasma dynamics during the ablation of oxides materials into an oxygen gas. The study was done using fast imaging and ion probe techniques. Both techniques revealed that a threshold oxygen pressure is needed to initiate the plume oxygen interaction. This threshold oxygen pressure depends on the ablated material. A clear effect of this threshold pressure on the structural and phase composition of the deposited thin films is shown.
\end{abstract}

Key words: Laser ablation, Plasma-oxygen interaction, Metal-insulator transition.

\section{INTRODUCTION}

Oxygen deficiency in the oxide thin films has a dramatic effect on the physical properties of these films [1]. Thus, during thin film deposition by laser ablation, a reactive oxygen atmosphere is necessary to bring closer the thin films properties to that of the bulk state [2]. However, the beginning of this reactivity is observed to occur only at a certain oxygen pressure [3].

Author Correspondence,e-mail: slafane@cdta.dz

ICID: 1020709 
Our study aims to determine this threshold pressure by the study of the plasma dynamics of two materials, the rare earth nickelate $\left(\mathrm{RNiO}_{3}\right)$ and the vanadium pentoxide $\left(\mathrm{V}_{2} \mathrm{O}_{5}\right)$. This latter material is used to synthesize vanadium dioxide $\left(\mathrm{VO}_{2}\right)$ thin films. Both $\mathrm{RNiO}_{3}$ and $\mathrm{VO}_{2}$ are thermochromic materials that undergo phase transition from the insulator to metallic state when changing the temperature. The interest is partly motivated by the potential of these materials to be used in novel electronics and electrooptic applications as switches or memory elements [4].

\section{EXPERIMENTAL SETUP}

The schematic of our experimental set-up have already illustrated in our previous work [5]. Two cylindrical lenses are used to focus a $\operatorname{KrF}(\lambda=248 \mathrm{~nm}, \tau=25 \mathrm{~ns})$ laser beam on the rotating target at $2 \mathrm{Jcm}^{-2}$ of laser fluence and into different oxygen pressures. In order to study the expansion dynamics by fast imaging, a set of mirrors and a Zeiss lens (76mm focal length, spectral response: $350 \mathrm{~nm}-800 \mathrm{~nm}$ ) are used to form a two-dimensional image of the luminous plasma on the ICCD camera (Princeton Instruments PI-MAX). The study by an ion probe was done by using a cylindrical Longmuir probe biased at $-35 \mathrm{~V}$ to collect only the ionic species.

The deposited vanadium dioxide $\left(\mathrm{VO}_{2}\right)$ thin films were grown by ablating a pressed $\mathrm{V}_{2} \mathrm{O}_{5}$ rotating target on Corning glass substrates. The target was irradiated with 3000 laser pulse at a laser fluence of $2 \mathrm{Jcm}^{-2}$ and a repetition rate of $5 \mathrm{~Hz}$. The target-substrate distance and the substrate temperature have been maintained at $4 \mathrm{~cm}$ and $500^{\circ} \mathrm{C}$, respectively. The oxygen pressure was varied from vacuum to $4 \times 10^{-3}$ mbar. The films structure and the phase composition were determined using X-Ray Diffraction (XPERT-PRO PW 3040-Phillips).

\section{RESULTS AND DISCUSSION}

Typical ICCD images of the plume temporal evolution of the ablated two materials into vacuum and oxygen pressure are given in figure 1.

For Vanadium oxide plume, the images show that at vacuum and $10^{-3}$ mbar the expansion is free from the early to the late time delay (no plume-oxygen gas boundary appears). However at $4 \times 10^{-3}$ mbar, the plume is confined and splits into two components. The plume splitting was considered as a result of the interaction between the plume species which are scattered in backward direction after collisions with 
background gas molecules and the incoming particles [6]. Thus $4 \times 10^{-3}$ mbar could be considered as the threshold pressure marking the beginning of the interaction between the ablated species and the background oxygen molecules. This interaction results on the formation of a shock front and the enhancing of the plume luminosity at the plumeoxygen gas edge. In the shocked layer, highly reactive atomic oxygen is produced and thereby an oxygen enrichment of the deposited films is expected [7]. The same behavior of the nickelate rare earth plume was observed. However, the threshold pressure is observed to be $2 \times 10^{-2}$ mbar in this case. This could be due to the difference in the mass and energy of the two plumes. It is established that the hydrodynamic effects can take place only if the initial plume mass and energy are high enough [8]. Thus, the same pressure can initiate a hydrodynamic expansion with the appearance of the plume splitting feature in the case of vanadium oxide and doesn't initiate it in the case of the nickelate rare earth.

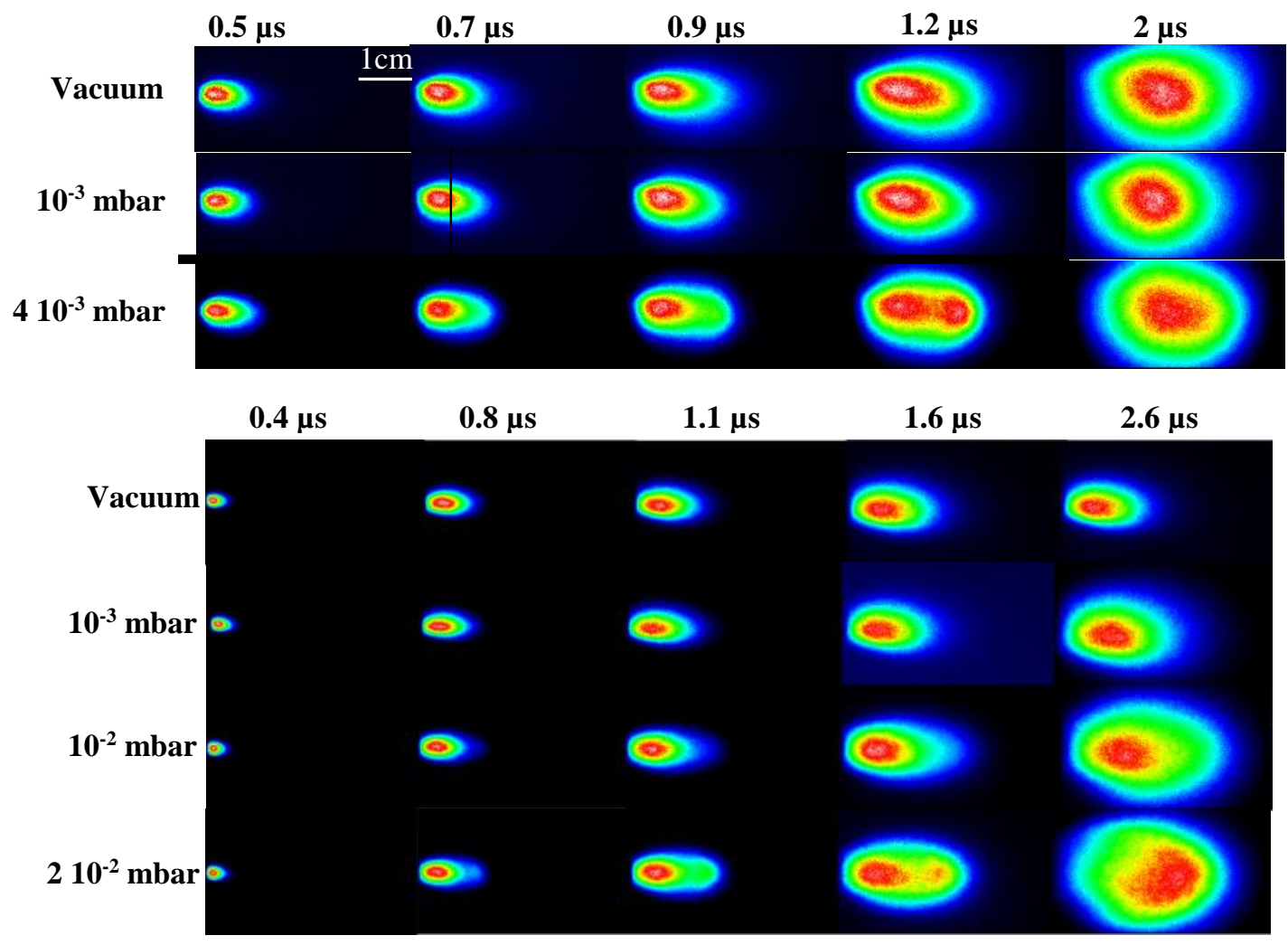

Fig.1. Temporal evolution of the visible vanadium oxide plume (a) and rare earth nickelate plume (b) at vacuum and different oxygen pressure 
We also analyzed the collected ions during the ablation of the nickelate rare earth target as a function of the pressure. The number of the collected ions was estimated by integrating the $\mathrm{V}(\mathrm{t})$ signal and by considering the ionization degree is no more than a unity. It is clearly seen on the figure 2 where the data are reported that the number of ions reaching the Langmuir probe is essentially constant and equal to that of the vacuum up to the pressure of $10^{-2}$ mbar. Beyond this latter pressure a progressive decrease of the ions number is observed. This decrease marks the transition from the free plume expansion regime to the hydrodynamic expansion regime which leads to a significant modification of the plume angular distribution in this regime [8]. This modification results in the reduction of the number of ions reaching the Langmuir probe located at the center of the plume [8]. Moreover, the decrease of the collected ions number can be partly ascribed to an enhancement of three-body recombination of the delayed ions as a consequence of plume confinement [8]. We note the coincidence of the threshold pressure of the plume-oxygen gas interaction obtained by fast imaging and that obtained by the ion probe.

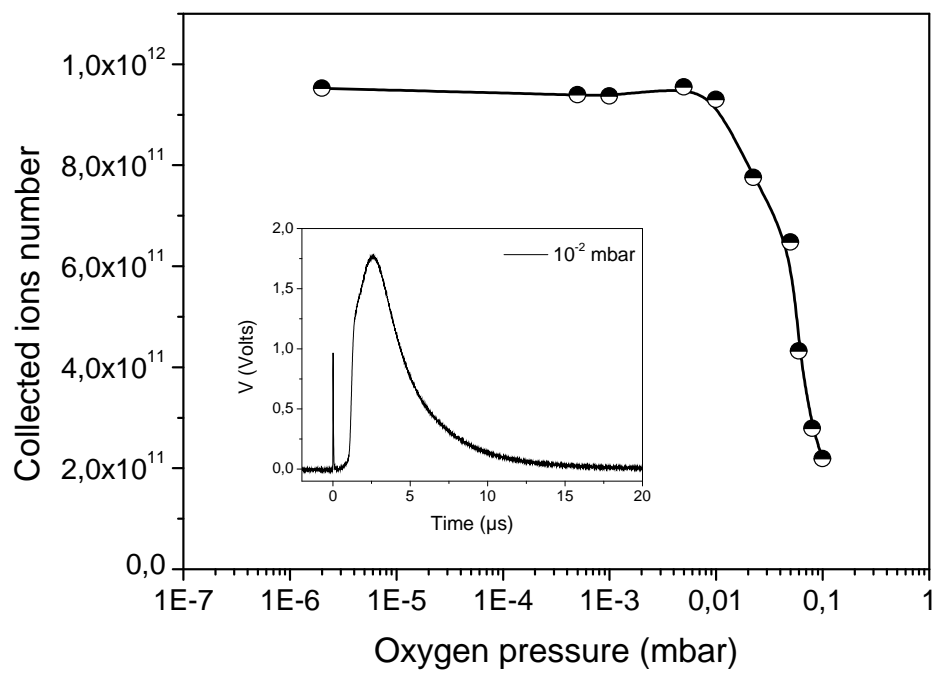

Fig.2. Collected ions number as a function of the oxygen pressure

Figure 3 shows the texture investigated by X-ray diffraction of the target and the vanadium oxide films deposited at vacuum, $10^{-3}$ and $4 \times 10^{-3}$ mbar of oxygen pressures. The deposited thin films show a significant difference in their crystalline structure. At vacuum and $10^{-3}$ mbar under-stoichiometric phases $\mathrm{V}_{2} \mathrm{O}_{3}$ and $\mathrm{V}_{4} \mathrm{O}_{7}$ are produced, respectively. A highly (011) oriented pure $\mathrm{VO}_{2}$ with the rutile structure was obtained at $4 \times 10^{-3}$ mbar. At vacuum and $10^{-3}$ mbar, there is no effect of the oxygen pressure on the plume expansion. Thus, the reactivity during the plume expansion is not expected 
which leads to the limitation of the oxygen incorporation into the deposited films. However, the reactivity on the substrate surface gives rise to the films oxygen content leading to the formation of $\mathrm{V}_{4} \mathrm{O}_{7}\left(\mathrm{VO}_{1.75}\right)$ phase at $10^{-3}$ mbar instead of $\mathrm{V}_{2} \mathrm{O}_{3}\left(\mathrm{VO}_{1.5}\right)$ phase obtained under vacuum. The obtained pure $\mathrm{VO}_{2}$ phase at $4 \times 10^{-3}$ mbar coincides with the beginning of the plume-oxygen gas interaction. This latter promotes the oxygen incorporation into the films by the mechanisms given previously.

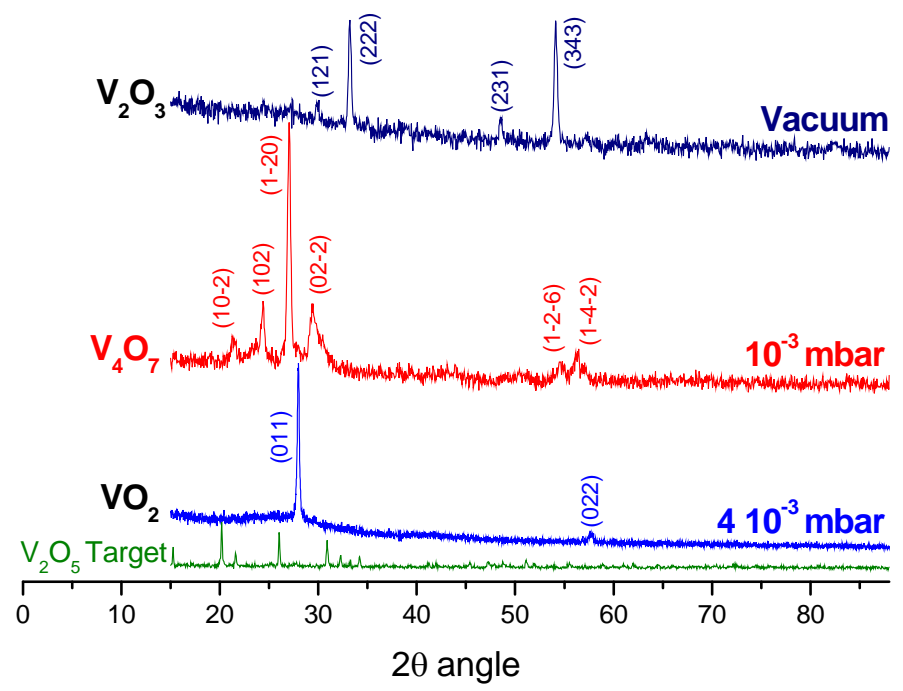

Fig.3. XRD spectra of the $\mathrm{V}_{2} \mathrm{O}_{5}$ target and the films deposited at vacuum and oxygen pressure range of $10^{-3}$ and $4 \times 10^{-3}$ mbar.

\section{CONCLUSION}

Vanadium oxide and nickelate rare earth plumes generated by laser ablation into a vacuum and background oxygen gas pressure were investigated by fast imaging and ion probe techniques. The study revealed that a threshold pressure is needed to initiate a hydrodynamic expansion of the plume. This threshold pressure depends on the target nature. A hydrodynamic behaviour of the plume into the oxygen gas background is necessary to promote the oxygen incorporation into the films.

\section{RÉFÉRENCES}

[1] Tsuchiya M., Sankaranarayanan S. and Ramanathan S. Photon-assisted oxidation and oxide thin film synthesis. A review. Progress in Materials Science. 2009, 54, 9811057. 
[2] Afonso C. N., Gonzalo J., Vega F., Dieguez E., Wong J. C. C., Ortega C., Siejka J., Amsel G. Correlation between optical properties, composition, and deposition parameters in pulsed laser deposited $\mathrm{LiNbO}_{3}$ films. Applied Physics Letter. 1995, 66 (12), 1452-1454.

[3] Amoruso S., Sambri A., Vitiello M., Wang X. Propagation of $\mathrm{LaMnO}_{3}$ laser ablation plume in oxygen gas. Applied Surface Science. 2006, 252, 4712-4716.

[4] Ruzmetov D. and Ramanathan S. 2010, Thin Film Metal-Oxides, Springer New York Dordrecht Heidelberg, London, 51-94p.

[5] Lafane S., Kerdja T., Abdelli-Messaci S., Malek S. and Maaza M. Laser-induced plasma study by fast imaging for $\mathrm{Sm}_{1-\mathrm{x}} \mathrm{Nd}_{\mathrm{x}} \mathrm{NiO}_{3}$ thin film deposition. Applied Surface Science. 2009, 256,1377-1381.

[6] Amoruso S., Sambri A., Vitiello M. and Wang X. Propagation of LaMnO3 laser ablation plume in oxygen gas. Applied Surface Science. 2006, 252, 4712-4716.

[7] Epurescu G., Siegel J., Gonzalo J., Gordillo-Vázquez F. J. and Afonso C.N. Imaging the dissociation process of $\mathrm{O}_{2}$ background gas during pulsed laser ablation of $\mathrm{LiNbO}_{3}$. Applied Physics Letter. 2005, 87, 211501-211503.

[8] Amoruso S., Oftmannc B.T., Schou J., Velotta R. and Wanga X. Diagnostics of laser ablated plasma plumes. Thin Solid Films. 2004, 453-454, 562-572.

\section{How to cite this article}

Lafane S, Kerdja T, Abdelli-Messaci S, Khereddine Y, Kechouane M. Plasma-oxygen interaction during thin films deposition by laser ablation: determination of the interaction pressure threshold and effect on the thin films propertiese. J Fundam Appl Sci. 2012, 4(1), 53-58. 